\title{
Práctica: Deshuese de Pollo Rostizado
}

Practice: Rostezed Chicken Breaking

Alexia Vázquez Hernández ${ }^{a}$, Jair Emmanuel Onofre Sánchez ${ }^{b}$

\begin{abstract}
:
The carving of birds is part of the essential techniques within the Russian service, so that the service personnel must know the form of scrapping of animal proteins, since it is the most important part of the main dishes in most establishments of classic food and drinks; where they ensure that the food of each guest should be served in the best way achieving enjoyment in every way while enjoying the preparation of their food in front of him.
\end{abstract}

Keywords:

Russian service, chicken, boneless

\section{Resumen:}

El trinchado de aves forma parte de las técnicas esenciales dentro del servicio Ruso, por lo que el personal de servicio debe conocer la forma de deshuezado de proteinas animales, ya que es la parte más importante de los platillos principales en la mayoría de los establecimientos de alimentos y bebidas clásicos; donde se aseguran que la comida de cada huésped se debe servir de la mejor manera logrando el disfrute en todos los sentidos mientras goza de la preparación de sus alimentos frente a él.

Palabras Clave:

Servicio ruso, pollo, deshuesado

\section{Introducción}

Felix Urbain Dobouis en su libro La cuisine clasique (1986) hizo popular el enfoque de brindar un servicio de comida mucho más especializado y lujoso, sin querer Dobouis introdujo el servicio ruso en los comedores europeos (Bagdan,P, 2012). El Nuevo servicio de moda en los comedores europeos consistia en que la comida se servía caliente desde una inmensa exhibición donde todos los platos, preparados se disponian al centro de la mesa en lujosas viandas de plata, de esta manera los invitados quienes estaban sentados lograban obtener el máximo efecto visual.

Dubois había redescubierto el servicio clásico de las mesas romanas: poner platos vistoso y elaborados para el deleite de los invitados.

Hoy en día el servicio ruso, está completamente preparada y decorada y adornada en grandes platos desde la cocina. Los platos de comida son llevados al comedor por el dependiente del comedor, se presentan a la mesa, se trinchan las proteinas mediante la hábil manipulación de un tenedor sobre una cuchara (cuchareo) y cuchillo para carne.

Es poco frecuente que los restaurants ofrezcan este tipo de servicio a sus comensales; normlamente solo s eincluyen algunos platillos, pero la realidad es que el servicio ruso se usa principalmente para banquetes, el objetivo principal es garantizar que el huésped reciba comida caliente y cocinada de manera rápida y de buen gusto. Es especialmente conveniente para banquetes o donde sea necesario para servir a muchas personas comida atractiva presentada de froma elegante al mismo tiempo que tiene un toque personal.

\section{Desarrollo}

I. OBJETIVO GENERAL DE LA PRÁCTICA Deshuesar con cuchareo frente al comensal el pollo y acompañar con guarniciones

II. IMPLEMENTOS A UTILIZAR

${ }^{a}$ Autor de Correspondencia, Universidad Autónoma del Estado de Hidalgo, Instituto de Ciencias Económico Administrativas, gastronomía, Email: alexia_vazquez@uaeh.edu.mx

b Universidad Autónoma del Estado de Hidalgo, Instituto de Ciencias Económico Administrativas, gastronomía, Email: Jair_onofre6570@uaeh.edu.mx 
Plato trinche, ensaladera, tabla, cuchareo y bowl, platon.

\section{Insumos requeridos para su preparación}

Ingredientes primarios del pollo rostizado

\begin{tabular}{|l|l|l|}
\hline Pollo rostizado & 1 & Pza \\
$\begin{array}{l}\text {-Ensalada de } \\
\text { vegetales frescos- }\end{array}$ & & \\
\hline $\begin{array}{l}\text { Lechugas mixtas } \\
\text { Espinaca }\end{array}$ & 0.005 & $\mathrm{Kg}$ \\
Zanahoria & 0.010 & $\mathrm{Kg}$ \\
\hline Jitomate & 0.060 & $\mathrm{Kg}$ \\
\hline Aceite de olivo & $\mathrm{c} / \mathrm{s}$ & $\mathrm{Pza}$ \\
\hline Limon & 0.200 & $\mathrm{~L}$ \\
\hline Cuscús & & $\mathrm{Kg}$ \\
\hline
\end{tabular}

\section{Procedimiento}

Asegurarse de tener todas las preparaciones previas antes de comenzar.

Presentar el pollo completo al anfitrión de la mesa, y regresar a la mesa de gueridon. Cada guarnición debe de estar colocada en una salsera y/o tazón con una cuchara para servir

Pase el pollo a la tabla sin escurrir.

Trinchar las piernas del ave.

Trinchar las alas del ave.

Cortar el pecho en dos porciones longitudinalmente.

Trasladar todas las piezas a una bandeja.

Mientras la operación de trinchado se lleva a cabo, agregar un poco de líquido a la bandeja para prevenir que las piezas del pollo se quemen.

Servir el pollo, dando un poco de carne de color marrón y algo de carne blanca por porción. Acomodar las guarniciones con la proteina.

\section{Conclusiones}

Se concluye que a partir de los conocimientos adquiridos en el servicio Ruso, el estudiante a este servicio como uno de los más elegantes y personalizados para el commensal, así mismo es visualmente atractivo al mismo tiempo que se muestran las habilidades del dependiente de comedor, por último el este serviciopermite que el commensal se sirva la porción deseada.

\section{Referencias}

[1] The culinary Institute of America (2014). Remarkable Service . New Jersey: Wiley \& sons.

[2] Bagdan,P. (2012). Guest Service in the Hospitality Industry. Wiley \& sons.: New Jersey. 